BANGLADESH J CHILD HEALTH 2010; VOL 34 (2): 51-55

\title{
Past and Present Pattern of Congenital Heart Disease at Dhaka Shishu Hospital: A Situation Analysis
}

\author{
MANZOOR HUSSAIN ${ }^{1}$, SARABON TAHURA ${ }^{2}$, MD. ABU SAYEED ${ }^{3}$, MD. MIZANUR RAHMAN $^{4}$, MD. \\ MAHBUBUR RAHMAN ${ }^{5}$, SUNTANU KUMAR KAR
}

\begin{abstract}
Background: Congenital heart disease (CHD) is the most common congenital problem in children. In order to avoid complications, reduce mortality and for proper management early detection of congenital heart disease is of utmost importance.

Objectives: The purpose of this study was to find out a single tertiary center experience in disease pattern of CHD among children with comparative analysis of past and present situation.

Methods: This study was conducted over a period of 2 years from January 2008 to December 2009 prospectively and another 2 years data was collected from hospital records from January 1998 to December 1999 retrospectively on all patients with the confirmed diagnosis of CHD admitted in Dhaka Shishu Hospital to compare present and past status. Patients from 1st day of life to 12 years of age were included in the study.

Results: Acyanotic heart diseases were commonly found both in past and present (75\% and $78.5 \%$ respectively) and among them Ventricular Septal Defect (VSD) was found the most common CHD (32.7\% and 26.9\% respectively). Atrial Septal Defect (ASD) was found $2^{\text {nd }}$ most common CHD (25.6\% and $21.2 \%$ respectively). Only $11.9 \%$ CHD were diagnosed during neonatal period in the past whereas $27.6 \%$ were diagnosed in the recent time. Rare CHD were detected more frequently in recent time.

Conclusion: VSD is the commonest non-cyanotic lesion whereas TOF is the commonest cyanotic lesion both in past and present, though their frequency reduced than before. Early detection and detection of rare CHD during recent time may reflect the advancement of diagnostic skill and facilities as well as awareness.
\end{abstract}

Key words: Congenital Heart Disease, children.

\section{Introduction}

Congenital heart disease (CHD) is the most common congenital problem accounting for nearly $25 \%$ of all congenital malformations and is the most common type of heart disease among children ${ }^{1}$. It may present

1. Professor and Head of Paediatric Medicine and Paediatric Cardiology, Bangladesh Institute of Child Health and Dhaka Shishu (Children) Hospital

2. Medical Officer, Paediatric Cardiology, Dhaka Shishu (Children) Hospital

3. Registrar, Paediatric Cardiology, Dhaka Shishu (Children) Hospital

4. Assistant Professor, Department of Pediatric Medicine, Bangladesh Institute of Child Health and Dhaka Shishu (Children) Hospital

5. Registrar, Dhaka Shishu (Children) Hospital

6. Medical Officer, Paediatric Cardiology, Dhaka Shishu (Children) Hospital

Correspondence: Dr. Sarabon Tahura in different ages from birth to adolescent ${ }^{2}$. Most cases are asymptomatic and discovered during routine neonatal check up ${ }^{3}$. As it is the most common amongst major birth defect, place a significant economic burden and psychological impact on the affected families and treatment is costly, it is very important to find out its pattern among children. In the western countries pattern of CHD is well documented ${ }^{4}$, but has not been studied nationwide in Bangladesh as in other western and neighboring countries. It is not a static condition, changes takes place throughout patient's life.

Hussain et $\mathrm{al}^{5}$ in early nineties found VSD (52.8\%), ASD (11.1\%), TOF (22.2\%) and PDA (8.3\%) as the commonest CHD. But Rahman et $\mathrm{al}^{6}$ found ASD 
(39.9\%) as common CHD followed by VSD (28.4\%), TOF (28.6\%) and PDA (5.2\%) during the same period. Sharmin et $\mathrm{al}^{7}$ during recent past found VSD in $42.6 \%$, TOF 18.3\% and ASD14.8\%. During the same period Hoque et $\mathrm{al}^{8}$ found VSD as the commonest CHD but Begum et $\mathrm{al}^{9,10}$ found ASD as the commonest CHD in neonate. So, a variation in pattern of $\mathrm{CHD}$ is seen in Bangladesh in different time.

Over the past 30 years there has been an increasing awareness regarding the importance of early referral of newborn with heart disease to special centers. Continuous advances in technology and training in paediatric cardiology and paediatrics have improved long term outcome and promised better quality of life ${ }^{10}$. CHD if left untreated is an important cause of morbidity and mortality in children, therefore early detection and proper intervention is most important. But in Bangladesh there is still lack of awareness regarding health problems and lack of diagnostic facilities which make the detection of CHD difficult. The purpose of this study was to present and compare the experience regarding pattern of $\mathrm{CHD}$ in children during past and present in Dhaka Shishu Hospital, which is the largest paediatric teaching hospital providing care to the children from all over Bangladesh having 533 beds along with a well equipped Pediatric Cardiology Unit.

\section{Materials and Methods}

This study was conducted in Dhaka Shishu Hospital over a period of 2 years from January 2008 to December 2009 prospectively and another 2 years data was collected from hospital records from January 1998 to December 1999 retrospectively. Patients from 1st day of life to 12 years of age were included in the study. The cases were included after the clinical diagnosis of CHD and were confirmed by Color doppler echocardiography. Patients with acquired heart diseases such as rheumatic heart diseases or mitral valve prolapse were not included in this study. Consideration was given to total number of cases with CHD, age at diagnosis, sex distribution and type of CHD. Written consent was taken from parents and/or attendants from all enrolled patients following all ethical commitments. Data were analyzed by using SPSS version 12. Z test for proportion was applied to see the difference between CHD during past and present.

\section{Results}

Total 539 patients were diagnosed as CHD during January 2008 to December 2009 and out of them 148 (27.4\%) were diagnosed during neonatal period, 196 (36.6\%) during 1 month to 1 year and 121 (22.5\%) during over 1 year to 5 years of age. Majority of the cases were diagnosed before 6 years of age. During January 1998 to December 1999, 312 patients were diagnosed as CHD but only $11.9 \%$ were diagnosed during neonatal period and majority of the cases were diagnosed during infancy (Table-I).

\section{Table-I}

Age distribution among the cases of $\mathrm{CHD}$ during Jan '98 to Dec '99 and Jan '08 to Dec '09 ( $n=312$ and 539)

\begin{tabular}{lcc}
\hline Age & Jan '98- Dec '99 & Jan '08-Dec '09 \\
& $\mathrm{N}(\%)$ & $\mathrm{N}(\%)$ \\
\hline 0-28 days & $37(11.9)$ & $148(27.5)$ \\
1 month- 1 years & $183(58.6)$ & $196(36.4)$ \\
Over 1 year-5 years & $55(17.6)$ & $121(22.4)$ \\
6 years - 10 years & $27(8.7)$ & $69(12.8)$ \\
Over 10 years & $10(3.2)$ & $5(0.9)$ \\
\hline Total & $312(100)$ & $539(100)$ \\
\hline
\end{tabular}

Among 539 patients during January 2008 to December 2009,364 were male and 175 were female with a male female ratio of 2.08:1. During January 1998 to December 1999 among 312 patients with CHD, 232 were male and 80 were female with a male female ratio of 2.9:1 (Fig.-1).

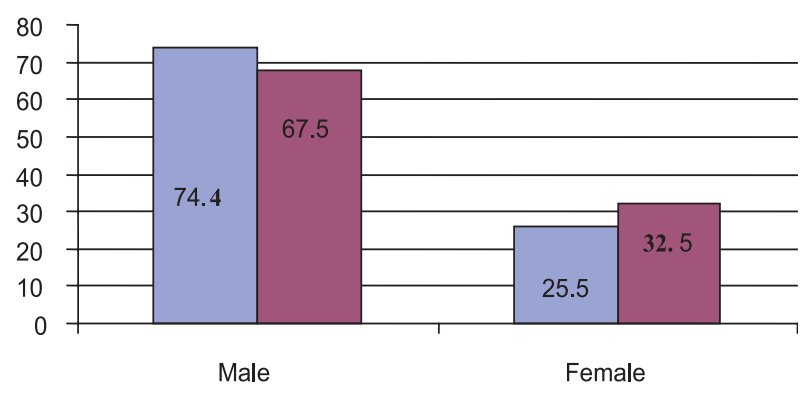

Fig.-1: Distribution of sex between past and present among children with CHD 
Cyanotic heart disease was present in $21.5 \%$ cases during January 2008 to December 2009 and it was 25\% during January 1998 to December 1999 (Fig.-2).

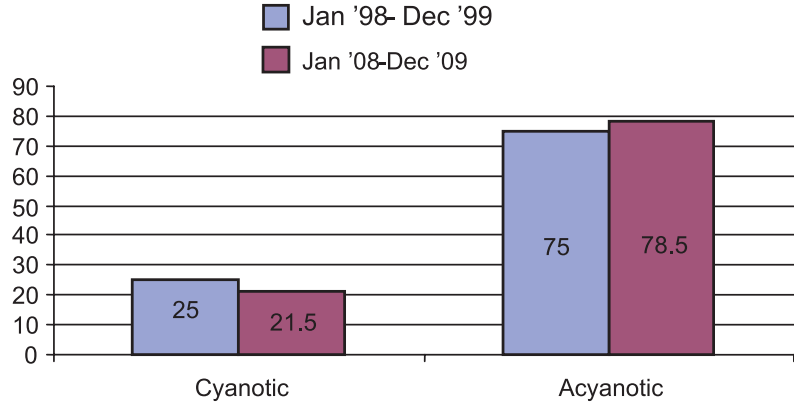

Fig.-2: Distribution of cyanotic and acyanotic CHD during past and present

During the period of January 1998 to December 1999 VSD was found in $32.7 \%$ cases followed by ASD in $25.6 \%$, TOF in $15.1 \%$, Patent Ductus Arteriosus (PDA) in $6.7 \%$ and Transposition of the GreatArteries (TGA) in 4.2\%. During January 2008 to December 2009 VSD remains at the top of the list (26.9\%) followed by ASD in $21.2 \%$, TOF in $7.1 \%$, PDA in $8.7 \%$ and TGA in $4.8 \%$ cases (Table-II).

Table-II

Pattern of CHD during Jan '98- Dec '99 and Jan '08Dec '09

\begin{tabular}{lcc}
\hline CHD & $\begin{array}{c}\text { Jan '98- } \\
\text { Dec '99 } \\
\text { N (\%) }\end{array}$ & $\begin{array}{c}\text { Jan '08- } \\
\text { Dec '09 } \\
\text { N (\%) }\end{array}$ \\
\hline VSD & $102(32.7)$ & $145(26.9)$ \\
ASD & $80(25.6)$ & $114(21.2)$ \\
PDA & $21(6.7)$ & $47(8.7)$ \\
TOF & $47(15.1)$ & $38(7.1)$ \\
TGA & $13(4.2)$ & $26(4.8)$ \\
Pulmonary stenosis & $6(1.9)$ & $24(4.5)$ \\
AV canal defect & $7(2.3)$ & $24(4.4)$ \\
Double outlet right ventricle & $2(0.6)$ & $4(0.7)$ \\
Total anomalous pulmonary & $2(0.6)$ & $7(1.3)$ \\
venous return & & \\
Single ventricle & - & $3(0.6)$ \\
Coarctation of the aorta & $3(0.9)$ & $9(1.7)$ \\
Aortic stenosis & $9(2.9)$ & $20(3.7)$ \\
Ebstain anomaly & - & $5(0.9)$ \\
Truncus arteriosus & - & $4(0.7)$ \\
Dextrocardia & $3(0.9)$ & $7(1.3)$ \\
Tricuspid atresia & - & $4(0.7)$ \\
Hypoplastic left heart syndrome & - & $3(0.6)$ \\
Others & $17(5.5)$ & $55(10.2)$ \\
\hline
\end{tabular}

VSD was present in $32.7 \%$ and $26.9 \%$ during January 1998 to December 1999 and January 2008 to December 2009 respectively. ASD was present in $25.6 \%$ and $21.2 \%$ during January 1998 to December 1999 and January 2008 to December 2009 respectively. Frequency of TOF was found less during January 2008 to December 2009 (7.1\% and $15.1 \%$ respectively) and PDA became the $3^{\text {rd }}$ most common CHD during this time (8.7\% in comparison to $6.7 \%$ ) (Fig.-3). Significant reduction in the frequency of VSD and TOF is found during January 2008 to December 2009 in comparison to January 1998 to December $1999(p<0.05)$ and remain unchanged in ASD, PDA and TGA $(p>0.05)$.

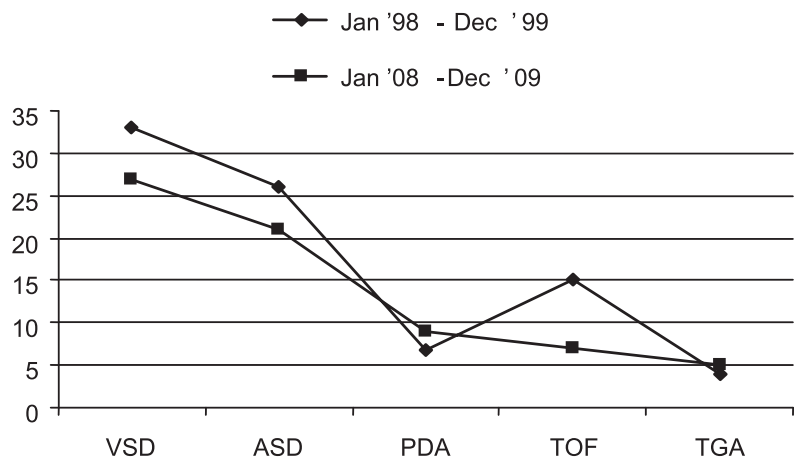

Fig.-3: Comparison of top five CHD during past and present

\section{Discussion}

The prevalence and the rates of occurrence of $\mathrm{CHD}$ in different reports vary due to duration and intensity of case finding, the sensitivity of the diagnostic method used and also the admission policies of the concerned hospitals. The use of color doppler echocardiography has helped in diagnosing even very small defects and has increased early detection rates. It is generally accepted that the improvement of diagnosis, attention or awareness among general pediatrician and early referral to pediatric cardiologists has resulted in an increase of reported prevalence of $\mathrm{CHD}^{11,12}$. During January 1998 to December 1999 total 312 patients were diagnosed as CHD and only $11.9 \%$ were diagnosed during neonatal period but during January 2008 to December 2009 27.5\% CHD was diagnosed during neonatal period. Hussain et $\mathrm{al}^{5}$ during early nineties found only $8.3 \% \mathrm{CHD}$ at neonatal period. Similar result was found by Rahim et $\mathrm{al}^{4}$ in Pakistan who detected only $8 \%$ CHD during neonatal period. Advancement of neonatal care and more availability of diagnostic facilities may be the cause of early 
detection of CHD. Majority of CHD were diagnosed within 5 years of age but Hussain et al ${ }^{5}$ found majority of CHD during infancy. Less then 15\% CHD was diagnosed after 5 years of age, but Rahim et $\mathrm{al}^{4}$ found 29.3\% CHD after five years of age.

Acyanotic heart diseases were more common in this study both in past and present (75\% and $78.5 \%$ respectively). Cyanotic heart disease was present in 21.5\% cases during January 2008 to December 2009 and it was $25 \%$ during January 1998 to December 1999. Rahman et $\mathrm{al}^{6}$ in their study found $84.4 \%$ acyanotic CHD. Similar result was found by Begum et $\mathrm{al}^{10}$. During recent time Sharmin et $\mathrm{al}^{7}$ also found similar result in Bangladesh and Amro et $\mathrm{al}^{13}$ found $74 \%$ of cases were acyanotic $\mathrm{CHD}$ and the remaining was cyanotic. Rahim et $\mathrm{al}^{4}$ found one third of their CHD as cyanotic CHD.

Worldwide, VSD is the most common acyanotic CHD accounting for $25-30 \%$ of all $\mathrm{CHD}^{14}$. VSD was the commonest $\mathrm{CHD}$ in this study both in past and present $(32.7 \%$ and $26.9 \%)$. Significant reduction in the frequency of VSD is found during January 2008 to December 2009 in comparison to January 1998 to December $1999(p<0.05)$. Hussain et $\mathrm{al}^{5}$ in their study found more then $50 \%$ cases as VSD 20 years back and Rahim et al ${ }^{4}$ during $1997-98$ found $46 \%$. But in recent time Sharmin et $\mathrm{al}^{7}$ in Bangladesh found $42 \%$ VSD in their study and Misra et al ${ }^{15}$ found $28 \%$ VSD. But Rahman et al ${ }^{6}$ found ASD as commonest CHD (39.9\%) in the study conducted from 1982 to 1991. Begum et $\mathrm{al}^{10}$ found ASD as the commonest $\mathrm{CHD}$ in neonate. Siddique et $\mathrm{al}^{16}$ also found ASD as the commonest $\mathrm{CHD}$ about 20 years back.

In this study commonest cyanotic heart disease was TOF both in past and present (15.1\% and $7.1 \%$ ) but significant reduction in the frequency of TOF is found during January 2008 to December 2009 in comparison to January 1998 to December $1999(p<0.05)$. TGA was the $2^{\text {nd }}$ most common ( $4.2 \%$ and $4.8 \%$ ) cyanotic $\mathrm{CHD}$. This is comparable to world wide incidences (5$7 \%)^{17}$. Hussain et $\mathrm{al}^{5}$, Rahman et $\mathrm{al}^{6}$, Sharmin et $\mathrm{al}^{7}$, Mollah et $\mathrm{al}^{18}$ found similar result but Begum et $\mathrm{al}^{10}$ and Hoque et $\mathrm{al}^{8}$ in neonate found TOF and TGA in equal number.

Congenital heart diseases like Single Ventricle (SV), Hypoplastic Left Heart Syndrome (HLHS), Truncus Arteriosus, Tricuspid Atresia were less commonly found during January 1998 to December 1999. Along with these some other rare $\mathrm{CHD}$ were detected during recent time. It may be due to the advancement of cardiac facilities during recent time.

\section{Conclusion}

The majority of patients with congenital heart disease detected are non-cyanotic. TOF is the commonest cyanotic lesion and VSD is the commonest noncyanotic lesion. Most of them are detected during infancy with increased rate of early detection during recent time along with detection of rare CHD. With the advancement of diagnostic facility and neonatal care, early detection of $\mathrm{CHD}$ is possible and may help to treat it at an earlier age and thus give the affected children and their parent's hope of a better future.

\section{References}

1. Schoen FJ. The Heart. In: Cortan RS, Kumar V, Robins SL, editors. Robins Pathologic Basis of Disease. $6^{\text {th }}$ ed. Philadelphia: W.B. Saunders Company; 1999. p. 543-600.

2. Ardebili HE, Kamali P, Pouranssari Z, Komarizadeh. A Prenatal care and maternal age, education and re-productive behavior. Iran J Public Health 1987; 16: 57-64.

3. Banerjee B, Hazra S. Type of congenital heart disease of pregnancy wastage. J Obstet Gynecol Ind 2004; 54: 355-60.

4. Rahim F, Younas M, Gandapur AJ, Talat A. Pattern of congenital heart disease in children at tertiary care center in Peshawar. Pak J Med Sci 2003; 19: 19-22.

5. Hussain M, Hossain M, Amin SK, Molla MR. Pattern of congenital heart disease in Dhaka Shishu Hospital. D S (Child) H J 1992; 8: 42-46.

6. Rahman S, Ahmed MN, Rahmatullah KHI, Alam MS. The incidence of congenital heart diseases diagnosed by non-invasive technique - Ten years study in Bangladesh. D S (Child) H J 1992; 8: 5-15.

7. Sharmin LS, Haque MA, Bari MI, Ali MA. Pattern and clinical profile of congenital heart disease in a Teaching Hospital. TAJ 2008; 21: 58-62.

8. Hoque MM, Begum JA, Jahan R, Chowdhury MAKA, Hussain M. Importance of cardiac murmur in diagnosing congenital heart disease in neonatal period. Bangladesh J of Child Health 2008; 32: 17-20.

9. Begum NNF, Ahmed QS. Pattern of heart disease among neonates and their outcome: one 
year experience in non-invasive cardiac laboratory of Combined Military Hospital, Dhaka. Bangladesh J Child Health 2001; 25: 48-52.

10. Fatema NN. Incidence of CHD among hospital live birth in a tertiary hospital. Bang CV Journal 2008; 1: 14-20.

11. Wren C, Richmond S, Donaldson L. Presentation of congenital heart disease in infancy: Implications for routine examination. Arch Dis Child Fetal Neonatal Ed 1999; 80; 49-52.

12. Alabdulgader A. Congenital heart disease in 740 subjects: Epidemiological aspects. Ann trop Paediatr 2001; 21: 111-18.

13. Amro K. Pattern of congenital heart diseade in Jordan. Eur J Gen Med 2009; 6: 161-65.

14. Bernstein D. Congenital Heart Disease. In: Kliegman RM, Behrman RE, Jenson HB, Stanton BF, editors. Nelson Text Book of Pediatrics.18th ed. Philadelphia: Saunders, Elsevier; 2000. p. 1878-93.

15. Misra M, Mittal M, Verma AM, Rai R, Chandra G, Singh DP, et al. Prevalence and pattern of congenital heart disease in school children of eastern Uttar Pradesh. Indian Heart J 2009; 61: 58-60.

16. Siddique FM, Kamal SMM, Huq KMHSS. Clinical presentation of congenital heart disease in hospitalized patients. Bangladesh Heart Journal 1989; 4: 13-17.

17. Abbag F. Pattern of congenital heart disease in the southwestern region of saudi arabia. Ann Saudi Med 1998; 18: 393-95.

18. Mollah MAH, Begum NA, Islam MN, Mahmud RS, Haq MA, Nahar N, et al. Clinical profile of congenital heart diseases (CHD): An analysis of 218 cases. Bangladesh Heart J 2002; 17: 62-67. 